\title{
РОЛЬ ОБСЛУЖИВАНИЯ КОРПОРАТИВНЫХ КЛИЕНТОВ В БАНКОВСКОМ БИЗНЕСЕ
}

\author{
(c) 2020 Плюснина Оксана Владимировна \\ кандидат экономических наук, доцент кафедры экономики \\ Ухтинский государственный технический университет, Респ. Коми, Ухта \\ E-mail: oxana.p07@mail.ru
}

Обслуживание корпоративных клиентов в деятельности кредитных организаций является основой банковского бизнеса, приносит значительную часть прибыли, формирует и увеличивает ресурсную базу. Целью написания статьи является представление роли банковского обслуживания корпоративных клиентов.

Ключевые слова: корпоративные клиенты, категории клиентов, банковский бизнес, расчетнокассовое обслуживание, банковские услуги, пакет услуг.

Основу деятельности коммерческого банка создает обслуживание клиентов путем проведения в их отношении различных банковских операций. В деятельности банка принято выделять две категории клиентов - физические лица, т.е. люди, которые обращаются за получением банковских продуктов и услуг в частном порядке; юридические лица, т.е. субъекты, которым банковские продукты и услуги необходимы для осуществления экономической деятельности. Вторую категорию клиентов в банковском бизнесе принято назвать корпоративными клиентами.

Иными словами, банковское обслуживание клиентов - это процесс оказания банковской услуги клиенту в целях удовлетворения его потребностей.

Банки в своей деятельности проводят разделение клиентов на категории, в зависимости от того, какими организационно-правовыми характеристиками обладает клиент, каковы масштабы и направления его деятельности, какими услугами банка и в каких объемах он пользуется.

K категории корпоративных клиентов банки относят лиц, которые по своему организационно-правовому статусу являются юридическими лицами.

Юридические лица могут быть разделены банком на группы исходя из масштабов их деятельности и объемов использования банковских услуг - на малые, средние и крупные:

a) малые предприятия очень часто относятся к категории розничного бизнеса, поскольку объемы использованиями ими банковских услуг больше всего соотносятся с частными клиен- тами. Но если же такие клиенты обеспечивают хорошие объемы банковских продаж, они также относятся к корпоративным клиентам. Отнесение предприятий к категории малого бизнеса происходит, как правило, на основании критерия «годовой размер выручки от продаж». Как правило, для таких клиентов установлен рубеж в 0,8-1 млрд. руб. в год;

б) средние предприятия представляют значительный интерес как корпоративные клиенты банков, поскольку уровень использования ими банковских услуг достаточно высокий, они заинтересованы в развитии с банком долгосрочных отношений. К такой категории чаще всего относятся организации с объемом выручки от 1 до 10 млрд. руб. в год;

в) значительным успехом для банка является привлечение к обслуживанию крупных организаций. Объем выручки этих организаций должен превышать 10 млрд. руб. в год или большую величину, а значит, они способны обеспечить формирование ресурсной базы банка, высокие процентные и комиссионные доходы от обслуживания.

Существуют определенные параметры, по которым банками оцениваются клиенты, а затем присваивается статус «корпоративные». Основными параметрами, которые дают такую возможность, являются:

а) размер получаемой банком прибыли при обслуживании клиентов;

б) потребление наибольшего перечня банковских услуг и их объем;

в) объем обязательств клиента по активным 
операциям, которые подвержены кредитному риску;

г) объем выручки от реализации продукции предприятия за прошедший год;

д) сумма среднедневных остатков на счетах клиента.

Обслуживание корпоративных клиентов является частью банковского бизнеса, а значит, оказывает прямое влияние на результаты деятельности коммерческих банков. Роль обслуживания корпоративных клиентов можно проследить в следующих аспектах:

а) обслуживание корпоративных клиентов является, как правило, основным источником доходов банка. Обслуживание корпоративных клиентов приносит банку процентные и комиссионные доходы, причем размер доходов более высокий и стабильный, чем при обслуживании розничных клиентов;

б) обслуживание корпоративных клиентов позволяет банку формировать значительную часть ресурсной базы;

в) обслуживание корпоративных клиентов сказывается на состоянии ликвидности и платежеспособности банка;

г) обслуживание корпоративных клиентов влияет на конкурентоспособность банка на рынке банковских услуг. Обслуживание организаций, в том числе крупных, работающих в приоритетных отраслях экономики повышает деловую репутацию банка, способствует увеличению доли, которую банк занимает на рынке банковских услуг.

Помимо приведенных аспектов, можно выделить еще несколько преимуществ обслуживания корпоративных клиентов для банка:

а) наличие постоянных безналичных платежей по счетам, что увеличивает участие банка в национальной платежной системе;

б) крупные обороты по счетам и остатки средств на них, значительно больше, чем у розничных клиентов;

в) заинтересованность корпоративных клиентов в долгосрочном партнерстве, что создает перспективы для расширения банковского бизнеса;

г) большое количество кросс-продаж (сопутствующие продажи дополнительных продуктов и услуг) на одного клиента, за счет чего увеличивается доходность банковского бизнеса;

д) возможный выход банка на контрагентов клиента, что позволяет привлекать их к обслу- живанию.

Обслуживание корпоративных клиентов играет роль не только в части изменения результатов деятельности коммерческого банка, но и оказывает влияние на организацию банковского бизнеса. Корпоративные клиенты проявляют заинтересованность в развитии надежных, стабильных и долгосрочных отношений с банком, поэтому при выборе банка выдвигают к нему ряд требований. В условиях высокой конкуренции, банк при обслуживании корпоративных клиентов должен изменить подходы к организации своей деятельности, чтобы отвечать требованиям клиентов.

При организации деятельности по обслуживанию корпоративных клиентов банковский бизнес должен быть ориентирован на специфические потребности клиентов. Т.е. банки не навязывают клиенту свои услуги, и стараются акцентировать работу на максимальном удовлетворении текущих потребностей клиентов. При этом в процессе установления взаимоотношений с корпоративными клиентами банки должны определять, каковы те конкретные, индивидуальные формы банковских услуг, в которых они нуждаются, и разъяснять им необходимость и выгодность их приобретения.

Таким образом, роль обслуживания корпоративных клиентов в банковском бизнесе проявляется в нескольких аспектах: во-первых, это расширение клиентской базы за счет субъектов, обладающих высокими качественными характеристиками; это определяет увеличение таких важных показателей банка, как объем привлеченной ресурсной базы, размер кредитного портфеля, оборот безналичных расчетов по счетам, суммы процентных и комиссионных доходов; обеспечивает занятие более прочных позиций на рынке банковских услуг. При этом влияние проявляется и в том, что для обслуживания корпоративных клиентов банк должен организовать свою деятельность в соответствии с качественными ожиданиями клиентов.

Представим топ-10 коммерческих банков по показателю привлеченных средств корпоративных клиентов, представленных Порталом банковских аналитиков по состоянию на 01.01.2020 г. [6]

1. ПАО Сбербанк - 20723770751 тыс. руб.

2. Банк ВТБ (ПАО) - 10550967672 тыс. руб.

3. Газпромбанк (AO) - 5110642185 тыс. руб.

4. АО «Альфа-Банк» - 2810013321 тыс. руб. 
5. АО «Россельхозбанк» - 2576441706 тыс. руб.

6. ПАО Банк «ФК Открытие» - 1737085247 тыс. руб.

7. ПАО «Московский кредитный банк» 1513315439 тыс. руб.

8. АО «Райффайзенбанк» - 963796994 тыс. руб.

9. АО Юникредит банк - 963796994 тыс. руб.

10. ПАО «Совкомбанк» -824945759 тыс. руб.

Например, Банк ВТБ (ПАО), являясь крупным российским банком с федеральной сетью подразделений, по размеру активов занимает второе место в банковской системе страны. Банк является универсальным, т.е. проводит разные банковские операции в рублях и в иностранной валюте, в отношении организаций и физических лиц.

До 2018 года, когда произошло объединение с розничным банком - ВТБ 24 (ПАО), обслуживание корпоративных клиентов выступало основной специализацией Банка ВТБ (ПАО). Банк оказывал широкий спектр услуг крупным компаниям, работающих в ведущих отраслях российской экономики, а также обслуживал внешнеторговые операции. После реорганизации обслуживание корпоративных клиентов также остается одним из основных направлений деятельности. Однако теперь помимо обслуживания крупных организаций банк развивает услуги и для субъектов малого и среднего бизнеса.

Состав услуг для корпоративных клиентов, которые действуют в Банке ВТБ (ПАО), можно рассмотреть с двух позиций - исходя из категорий клиентов и исходя из видов банковских услуг:

a) услуги в банке разделены для двух категорий - для малого и среднего бизнеса, и для крупного бизнеса;

б) по видам услуг выделено в четырех направлениях - расчетно-кассовое обслуживание, кредитование, размещение средств и прочие услуги.

Первая категория банковских услуг для корпоративных клиентов в Банке ВТБ (ПАО) действует для субъектов малого и среднего бизнеса. Как отмечалось ранее, к этим субъектам банк относит индивидуальных предпринимателей и организации, с годовой выручкой до 1 млрд. руб. и с годовой выручкой от 1 млрд. руб. до 10 млрд. руб., соответственно.

Первоначальное значение в обслуживании корпоративных клиентов имеет их привлечение к расчетно-кассовому обслуживанию, так как обеспечивает движение денежных средств по счетам в банке и позволяет далее привлекать к кредитованию и размещению депозитов.

Расчетно-кассовое обслуживание малого и среднего бизнеса осуществляется в Банке ВТБ (ПАО) в виде предоставления пакетов услуг. На сегодняшний день в банке действует четыре таких пакета, различающихся по содержанию и стоимости обслуживания (таблица 1). Каждый из пакетов ориентирован на определенную категорию клиентов, например, для только что созданных компаний или для давно существующих компаний с развитым бизнесом.

Таблица 1. Пакеты услуг расчетно-кассового обслуживания малого и среднего бизнеса в Банке ВТБ (ПАО) [1]

\begin{tabular}{|c|c|c|c|}
\hline На старте & Самое важное & Все включено & Большие обороты \\
\hline Для молодых компаний & $\begin{array}{l}\text { Для активно растущих } \\
\text { компаний }\end{array}$ & $\begin{array}{l}\text { Для стабильно развиваю- } \\
\text { щегося бизнеса }\end{array}$ & Для развитого бизнеса \\
\hline $\begin{array}{l}\text { Стоимость обслужива- } \\
\text { ния - } 0 \text { руб. }\end{array}$ & $\begin{array}{l}\text { Стоимость обслужива- } \\
\text { ния - 0 руб. в первые } 3 \\
\text { месяца, далее } 1200 \text { руб. в } \\
\text { месяц }\end{array}$ & $\begin{array}{l}\text { Стоимость обслужива- } \\
\text { ния - } 0 \text { руб. в первые } 3 \\
\text { месяца, далее } 1900 \text { руб. в } \\
\text { месяц }\end{array}$ & 5950 руб. в месяц \\
\hline \multicolumn{4}{|c|}{ Обслуживание карты по счету - бесплатно } \\
\hline \multicolumn{4}{|c|}{ Платежи клиентам Банка ВТБ - без ограничений } \\
\hline \multirow{4}{*}{$\begin{array}{l}\text { Платежи клиентам других } \\
\text { банков } \\
5 \text { шт. в месяц }\end{array}$} & $\begin{array}{l}\text { Платежи клиентам других } \\
\text { банков } \\
30 \text { шт. в месяц }\end{array}$ & $\begin{array}{l}\text { Платежи клиентам других } \\
\text { банков } \\
60 \text { шт. в месяц }\end{array}$ & $\begin{array}{l}\text { Платежи клиентам других } \\
\text { банков } \\
150 \text { шт. в месяц }\end{array}$ \\
\hline & \multirow{3}{*}{$\begin{array}{l}\text { Внесение наличных в } \\
\text { месяц - } 50000 \text { руб. }\end{array}$} & $\begin{array}{l}\text { Внесение наличных в } \\
\text { месяц - } 250000 \text { руб. }\end{array}$ & $\begin{array}{l}\text { Внесение наличных в } \\
\text { месяц - } 750000 \text { руб. }\end{array}$ \\
\hline & & \multirow{2}{*}{ Дополнительные опции } & $\begin{array}{l}\text { Снятие наличных в месяц } \\
300000 \text { руб. }\end{array}$ \\
\hline & & & Дополнительные опции \\
\hline
\end{tabular}


В зависимости от пакета различается состав услуг и стоимость расчетно-кассового обслуживания. Так, для каждого пакета предусмотрено:

a) открытие расчетного счета в рублях РФ;

б) выпуск бизнес-карты к счету;

в) платежные операции в отношении клиентов Банка ВТБ (ПАО) и клиентов других банков.

Помимо представленных пакетов услуг в расчетно-кассовое обслуживание малого и среднего бизнеса в Банке ВТБ (ПАО) включены следующие услуги:

a) открытие и обслуживание специальных счетов для участия в торгах;

б) открытие и обслуживание счетов эскроу для взаиморасчетов по схеме долевого строительства;

в) проведение операций через дистанционные сервисы: «ВТБ Бизнес Онлайн», «ИнтернетКлиент (BS-Client)», «Интернет Банк-Клиент (iBank2)», «Клиент-Банк (Телебанк)»;

г) конверсионные операции;

д) расчеты в форме документарного аккредитива, чистого и документарного инкассо;

е) услуги ВЭД и валютного контроля;

ж) инкассация.

В таблице 2 представлен объем средств, привлеченных банком от корпоративных клиентов в ресурсную базу.

Представленные данные показывают, что в банке происходит увеличение средств, привлеченных от корпоративных клиентов. По итогам 2016 г. объем привлечения средств составил 4569 111 млн. руб., в 2017 г. он увеличился на 17,11\%, а в 2018 г. еще на 16,48\% до 6232278 млн. руб. Такая динамика обеспечена двумя видами поступлений от клиентов - средства на текущих и расчетных счетах, и средства в срочных депозитах. Второй вид значительно преобладает, хотя его доля снизилась с $72,33 \%$ в 2016 г. до 69,25\% в 2018 г. В абсолютном выражении он показал прирост за два года на 30\%: с 3304759 млн. руб. в 2016 г. до 4316148 млн. руб. в 2018 г.

Наибольший прирост показали средства на текущих и расчетных счетах корпоративных клиентов - в 2017 г. прирост составил 20,35\%, а в 2018 г. 26,51\%, т.е. более чем на 50\% за два года. Это привело к росту этих средств в структуре - с $26,29 \%$ до $29,35 \%$.

Обслуживание корпоративных клиентов позволяет банку формировать доходы, влияя на размер прибыли от осуществления деятельности. В таблице 3 представлены доходы и расходы банка от обслуживания корпоративных клиентов.

Данные таблицы 3 показывают, что в 2016 г. при обслуживании корпоративных клиентов банком был получен убыток в размере 100 млн. руб. В последующие периоды деятельность банка была прибыльной - в 2017 г. прибыль составила 108400 млн. руб., а в 2018 г. 178600 млн. руб., что на $64,76 \%$ больше, чем в прошлом периоде. Улучшение ситуации связано с тем, что с 2017 г. банк стал активнее развивать корпоративноинвестиционный бизнес, от которого получено порядка 60\% всех доходов.

Таким образом, можно сделать вывод, что приоритетное значение в обслуживании корпоративных клиентов имеет их привлечение к расчетно-кассовому обслуживанию, так как обеспечивает движение денежных средств по счетам в банке и позволяет далее привлекать к кредитованию и размещению депозитов.

Таблица 2. Структура и динамика средств корпоративных клиентов в Банке ВТБ (ПАО) по итогам 2016-2018 гг. [2]

\begin{tabular}{|l|c|c|c|c|c|c|c|c|}
\hline \multirow{2}{*}{\multicolumn{1}{|c}{ Показатель }} & \multicolumn{2}{|c|}{2016 г. } & \multicolumn{2}{c|}{2017 г. } & \multicolumn{2}{c|}{2018 г. } & \multicolumn{2}{c|}{$\begin{array}{c}\text { Темп прироста/ } \\
\text { снижения,\% }\end{array}$} \\
\cline { 2 - 10 } & млн. руб. & $\%$ & млн. руб. & $\%$ & млн. руб. & $\%$ & $2017 / 2016$ & $2018 / 2017$ \\
\hline $\begin{array}{l}\text { Средства на текущих, } \\
\text { расчетных счетах }\end{array}$ & 1201373 & 26,29 & 1445837 & 27,02 & 1829119 & 29,35 & 20,35 & 26,51 \\
\hline Срочные депозиты & 3304759 & 72,33 & 3856057 & 72,07 & 4316148 & 69,25 & 16,68 & 11,93 \\
\hline $\begin{array}{l}\text { Расчеты по аккреди- } \\
\text { тивам }\end{array}$ & 52475 & 1,15 & 42556 & 0,80 & 83480 & 1,34 & $-18,90$ & 96,17 \\
\hline Договоры «репо» & 10504 & 0,23 & 6226 & 0,12 & 3531 & 0,06 & $-40,73$ & $-43,29$ \\
\hline Всего & 4569111 & 100,00 & 5350676 & 100,00 & 6232278 & 100,00 & 17,11 & 16,48 \\
\hline
\end{tabular}


Таблица 3. Финансовые результаты по обслуживанию корпоративных клиентов в Банке ВТБ (ПАО) по итогам 2016-2018 гг. [2], млн. руб.

\begin{tabular}{|l|c|c|c|c|c|}
\hline \multicolumn{1}{|c|}{ Показатель } & 2016 г. & 2017 г. & 2018 г. & \multicolumn{2}{c|}{$\begin{array}{c}\text { Темп прироста/ } \\
\text { снижения, \% }\end{array}$} \\
\cline { 3 - 6 } & & & & $2017 / 2016$ & $2018 / 2017$ \\
\hline $\begin{array}{l}\text { Доходы от обслуживания } \\
\text { корпоративных клиентов }\end{array}$ & 1077700 & 1009900 & 1103300 & $-6,29$ & 9,25 \\
\hline $\begin{array}{l}\text { Расходы от обслуживания } \\
\text { корпоративных клиентов }\end{array}$ & 1077800 & 901500 & 924700 & $-16,36$ & 2,57 \\
\hline Финансовый результат & $(100)$ & 108400 & 178600 & - & 64,76 \\
\hline
\end{tabular}

\section{Библиографический список}

1. Банковские услуги для малого и среднего бизнеса в Банке ВТБ (ПАО) [Электронный ресурс]. - Режим доступа: https://www.vtb.ru/malyj-biznes/ (дата обращения 20.08.2020).

2. Годовая бухгалтерская (финансовая) отчетность Банка ВТБ (ПАО) [Электронный ресурс].- Режим доступа: https://www.vtb.ru/akcionery-i-investory/finansovaya-informaciya/raskrytie-finansovoj-otchetnosti-po-rsbu/ (дата обращения 22.08.2020).

3. Годовой отчет Банка ВТБ (ПАО) [Электронный ресурс].- Режим доступа: https://www.vtb.ru/akcionery-iinvestory/raskrytie-informacii/godovoj-i-socialnyj-otchet/ (дата обращения 22.08.2020).

4. Костикова, В.И. Теоретические основы и технологии комплексного обслуживания корпоративных клиентов в коммерческом банке [Электронный ресурс] / В.И. Костикова // Транспортное дело России.- 2016. № 2.- C. 62-63. Режим доступа: https://www.elibrary.ru/item.asp?id=26138396 (дата обращения 20.08.2020).

5. Курченя, О.А. Обслуживание корпоративных клиентов банками: его роль и особенности [Текст] / О.А. Курченя // В сборнике: Наука сегодня: постулаты прошлого и современные теории. Материалы VIII международной научно-практической конференции. Ответственный редактор А. А. Зарайский. - 2017. - С. 98-101.

6. Портал банковского аналитика [Электронный ресурс].- Режим доступа: analizbankov.ru (дата обращения 19.08.2020)

7. Статистика банковского сектора [Электронный ресурс]. - Режим доступа: https://cbr.ru/statistics/pdko/int_ $\mathrm{rat} /$ (дата обращения 19.02.2020). 